\title{
THE TECHNOLOGICAL AND EXPLOITATIVE FACTORS OF LOCAL INCREASE OF ELECTRIC FIELD STRENGTH IN THE POWER CABLE OF COAXIAL DESIGN
}

Introduction. Reliability of high voltage power cables in the process of long-term operation is largely due to the intensity of polymeric insulation aging. It is now established that the aging of polyethylene, which is the main material for the insulation of high voltage power cables, under the action of the electric field is determined primarily by the presence of structural heterogeneity arising both during cable production and during use. The cable is always there deviations from the ideal structure, which manifest in a deviation of diameters of conductors from nominal values; in the arrangement of the conductor and the insulation is not strictly coaxially and eccentrically; in elliptic (oval) core and insulation; change in relative dielectric constant and thickness of insulation on cable length force the formation of low molecular weight products (including water) in the flow at the manufacturing stage crosslinked polyethylene insulation and moisture during operation. Such defects are structural, technological and operational irregularities, which lead to a local change in the electric field. Purpose. Analysis of the influence of the eccentricity, elliptic and spherical inclusions in the electric field distribution in the power cable of a coaxial design with cross-linked polyethylene insulation, based on numerical simulation. Methodology. The bases of the numerical method of calculation of the electrical field strength are Fredholm integral equations of the first and second kind (method of secondary sources) for an axially symmetric field. Analysis of the influence of irregularities, including water treeing, the shape of the sounding signal is made using the method of discrete resistive circuit inductance and capacitance of substitution with the initial conditions. Solving systems of linear algebraic equations nodal analysis performed by the sweep method. Results. The presence of the eccentricity and ellipticity in the construction of cable has different effects on the distribution of the electrical field strength at the conductor and the insulation. The electrical field strength is increased by $50 \%$ in the core and $17 \%$ - on the surface of the insulation at $10 \%$ eccentricity between conductor and insulation. Availability elliptic insulation leads to a redistribution of the electric field: field strength at the surface of the insulation is 2 times higher electric field strength on the surface of the conductor. Water treeing spherical shape filled with water with a dielectric constant of 6.9, lead to a local increase of electric field intensity is 5 - 10 times. Originality. Simulation results show that the presence of water treeing concentrated with individual heterogeneity characteristic impedance causes a change in shape and duration of the probe signal rectangular. Practical value. Time domain reflectometer can be considered as one of the promising methods for diagnosing operational irregularities (ellipticity, eccentricity, water treeing) in power cables. References 10, figures 12 .

Key words: eccentricity, ellipticity of insulation, water treeing, electric field strength, the wave impedance, the probe pulse.

На основе численного моделирования выполнен анализ влияния эксцентриситета между токопроводящей жилой и изоляцией, эллиптичности изоляции и включений сферической формы на распределение напряэенности электростатического поля в силовом кабеле коаксиальной конструкции со сшитой полиэтиленовой изоляцией. Показано, что активный характер и высокие значения эффективной проводимости полупроводящих экранов не влияют на распределение поля между жилой и изоляцией. Наличие в толще изоляции водных включений сферической формы приводит к усилению электрического поля в 5 и более раз в зависимости от диэлектрической проницаемости. Водные триинги, как локальные сосредоточенные неоднородности в структуре полиэтиленовой изоляции, приводят к изменению формы зондирующего прямоугольного сигнала, распространяющегося в силовой кабельной линии, что дает возможность в эксплуатации диагностировать их с помощью импульсной рефлектометрии. Библ.10, рис.12.

Ключевые слова: эксцентриситет, эллиптичность изоляции, водные триинги, напряженность электрического поля, волновое сопротивление, зондирующий импульс.

Introduction. Reliability of high voltage power cables in the process of long-term operation is largely due to the intensity of polymeric insulation aging. The highvoltage power cables under the effect of electric field aging of polyethylene is determined primarily by the presence of irregularities arising in the process of production of cables, as well as during operation. The cable is always there deviations from the ideal structure, which manifest in a deviation of diameters of conductors from nominal values; in the arrangement of the conductor and the insulation is not strictly coaxially and eccentrically; in elliptic (oval) core and insulation; change in relative dielectric constant and thickness of insulation on cable length force the formation of low molecular weight products (including water) in the flow at the manufacturing stage crosslinked polyethylene insulation and moisture during operation. Such defects are structural, technological and operational irregularities, which lead to a local change in the electric field strength [1-3].

The goal of the paper is analysis of the influence of eccentricity, ellipticity and the spherical inclusions on the electric field distribution on the basis of the numerical simulation.

Effect of semiconductive screens on the distribution of the electric field strength. A feature of the construction of high-voltage cables with XLPE insulation semiconducting screens is the presence on the surface of the core and the surface of the insulation. Three layers semiconducting coating on the core, insulation and semiconducting layer insulation - applied simultaneously per core using triple extrusion. As a result, air gaps between

(C) G.V. Bezprozvannych, A.G. Kyessayev 
the layers are not formed. In addition, the high conductivity of semiconducting layers of an electric field provides a bypass air gaps between the conductor and semiconductive coating on the core, between the semi-conductive coating on the insulation and the metal shield of the cable. The partial discharges in these gaps do not arise.

In [4] it is shown that the effective conductivity of the $R C$ chain, replacing the semi-conductive layer is not capacitive but active. In this case it is $40-40,000$ times higher than the conductivity of the capacitive layer with relative dielectric constant $\varepsilon=10$. The effective dielectric constant of the semiconducting layers is about 400 400,000 , which makes it possible to neglect their effect on the field distribution in the gap «conductive wire - metal screen» (Fig. 1).

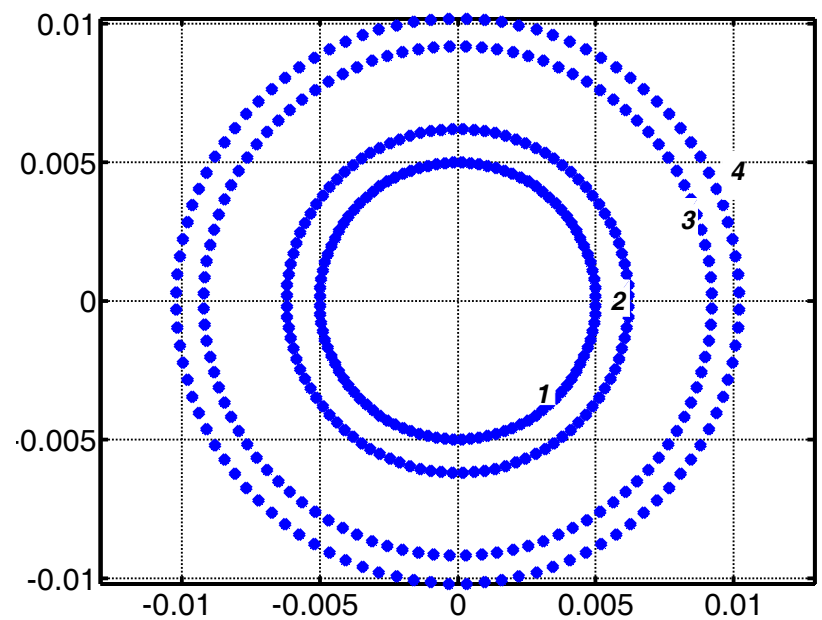

Fig. 1. The schematic arrangement of nodes on the surface of wire (1), semiconductive screen by wire (2), surface of the insulation (3), and semiconductive screen by insulation (4)

Fig. 2 shows the distribution of the line of tension along the boundaries between the media 1 - 4 (Fig. 2). When switching from the first layer (semiconductive coating cores) for the second (core insulation), the field strength increases abruptly in $\varepsilon 1 / \varepsilon 2$ times. In the transition from the second to the third layer (semi-conductive shield insulation) field strength abruptly decreases in $\varepsilon 3 / \varepsilon 2$ times [5]. The strength at the beginning of the third layer and the end of it (on the metal screen of the cable) is the same in magnitude but opposite in sign: the tension on the surface of the screen is taken negative, in contrast to the tension on the surface of the semiconductive screen by wire, which is assumed to be positive.

Influence of eccentricity and ellipticity. In the case of a homogeneous electric field in the insulation of the power cable coaxial design (Fig. 3) is nonuniform by thickness of insulation: the maximum on the conductor and the minimum at the surface of the cable insulation.

Presence of eccentricity $\Delta Z$ between conductive wire and insulation leads to thickening $\left(\Delta_{1}\right)$ and thinning $\left(\Delta_{2}\right)$ insulation (Fig. 4) resulting in the distortion of electric field (Fig. 5, curve 2) on the surface of the wire $(I)$ and insulation $(I I)$. The electric field intensity increases locally thinned areas and isolation areas in decreases thick- ening, i.e. there is also the heterogeneity of distribution on the surface of the conductor and the insulation (curves 2). At eccentricity $\Delta Z=10 \%$ of the radius of the conductor to tension in the core is increased by $20 \%$, on the surface of the insulation $-25 \%$. When eccentricity $100 \%$ of the diameter of the conductor coefficient of uneven distribution of the electric field strength equal to the ratio of electric field strength with eccentricity $E_{e}$ to field without eccentricity $E$ increases in 1.5 and 3 times on the surface of wire (K1) and isolation (K2), respectively (Fig. 6) [2].

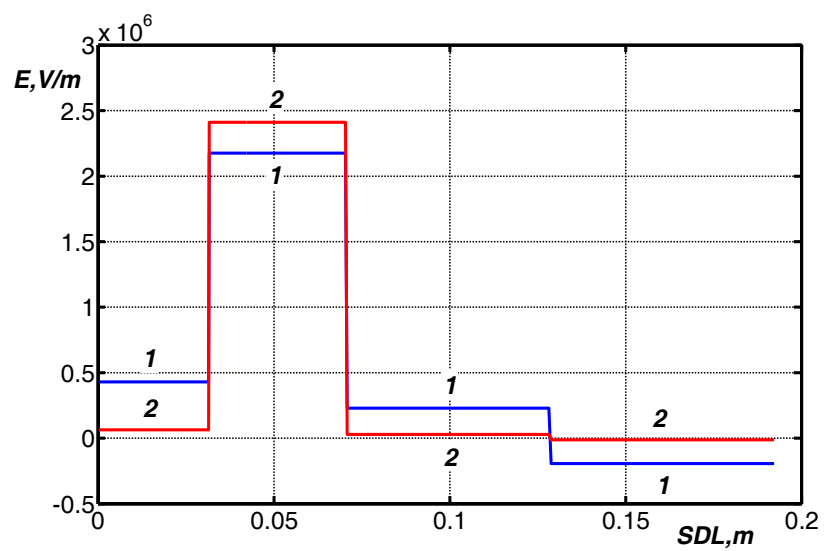

Fig. 2. The distribution of the electric field strength along the boundaries between the media 1 - 4 (Fig. 1) at different parameters of semiconducting layers: 1) $\varepsilon_{1}=\varepsilon_{3}=15$; 2) $\varepsilon_{1}=\varepsilon_{3}=150$.

The relative dielectric constant of the insulation $\varepsilon_{2}=2.3$

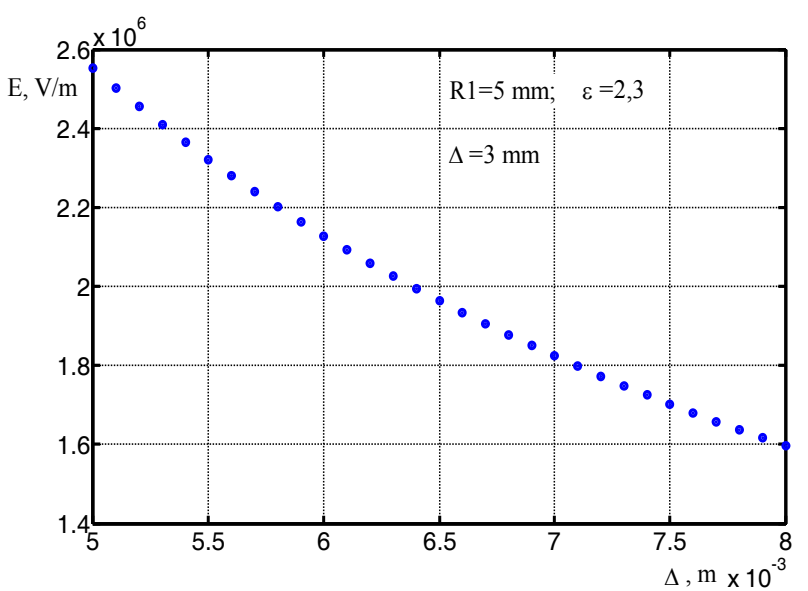

Fig. 3. The distribution of the electric field strength in the thickness of the homogeneous cross-linked polyethylene insulation in single-core high voltage power cables of perfect coaxial structure

The ellipticity (roundness) of insulation (Fig. 7) also leads to a distortion of the electric field on the surface of the conductor $(I)$ and insulation $(I I)$ : with ellipticity of $5 \%$ (curve 1) the field strength in the wire increases by $10 \%$, on the surface of the insulation - $20 \%$; with ellipticity of $11 \%$ (curve 2 ) by $30 \%$ and $45 \%$; with ellipticity of $18 \%$ (curve 3 ) by $53 \%$ and $87 \%$, respectively, relative to the field strength in a perfectly round cable design. 


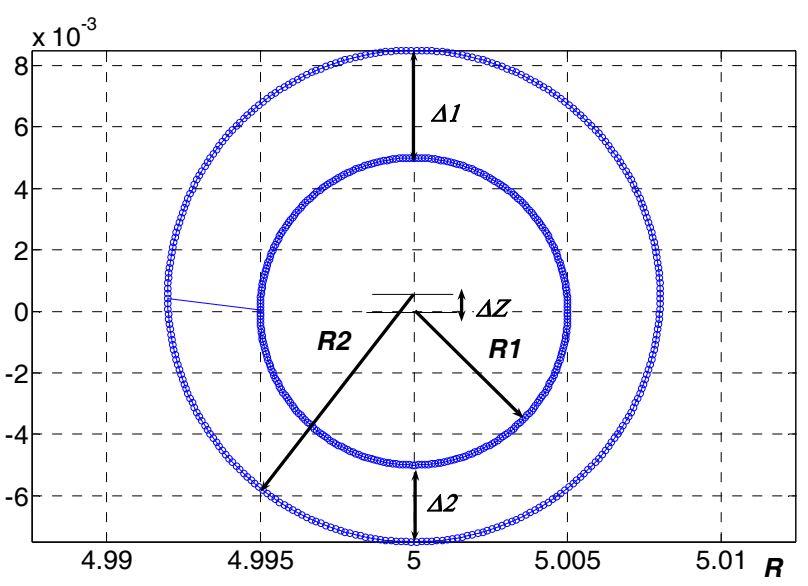

Fig. 4. The schematic arrangement of nodes in the calculation of the electric field strength in the power cable of coaxial design with eccentricity $\Delta Z$ between wire and insulation

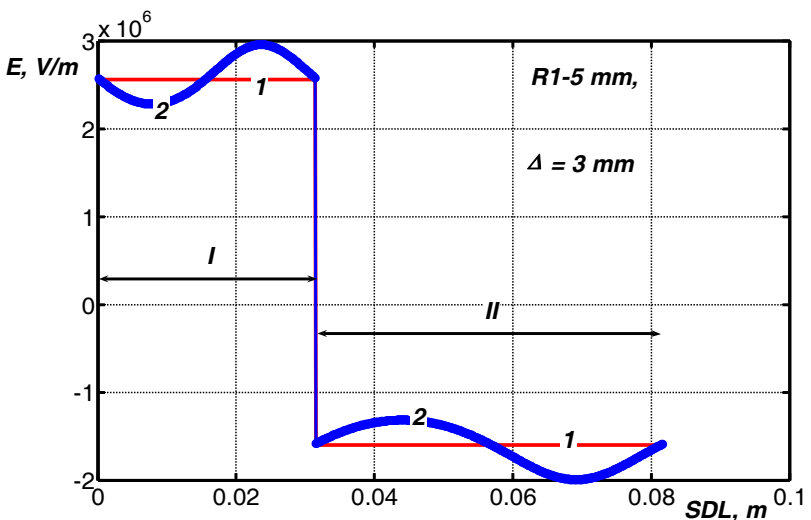

Fig. 5. The distribution of the electric field strength on the surface of the conductive wire and the insulation when absence (curve 1 ) and the presence of eccentricity $\Delta Z=0,1 R_{1}$ (curve 2) between the wire and insulation

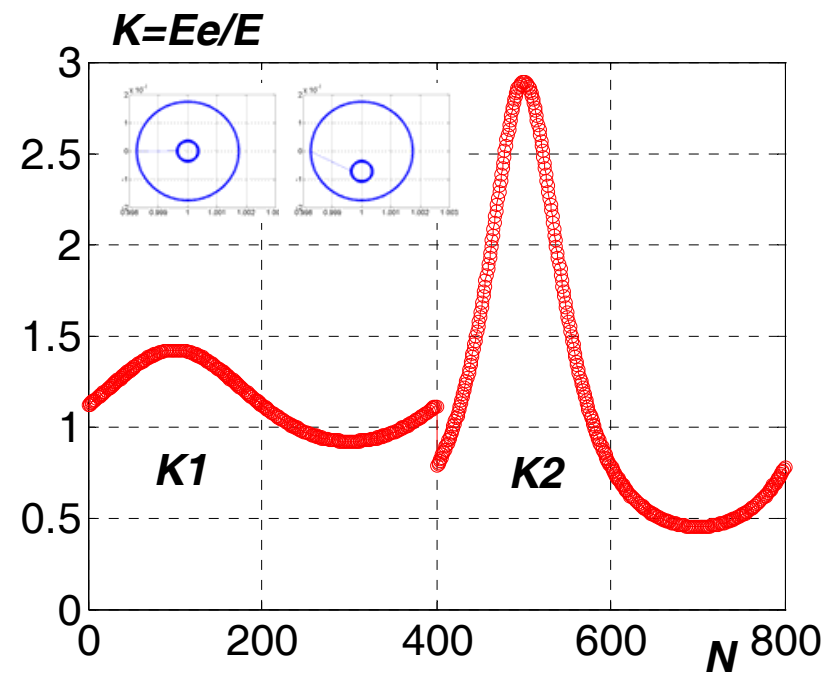

Fig. 6. Coefficient of uneven distribution of the electric field strength on the surface of wire $(K 1)$ and insulation $(K 2)$ at $100 \%$ eccentricity $\Delta Z=R_{1}$

The presence of the eccentricity and ellipticity causes a change in wave resistance of the single-core power cable of coaxial design $[1,2]$

$$
\dot{Z}_{w}=\sqrt{\frac{R+j \omega L}{G+j \omega C}},
$$

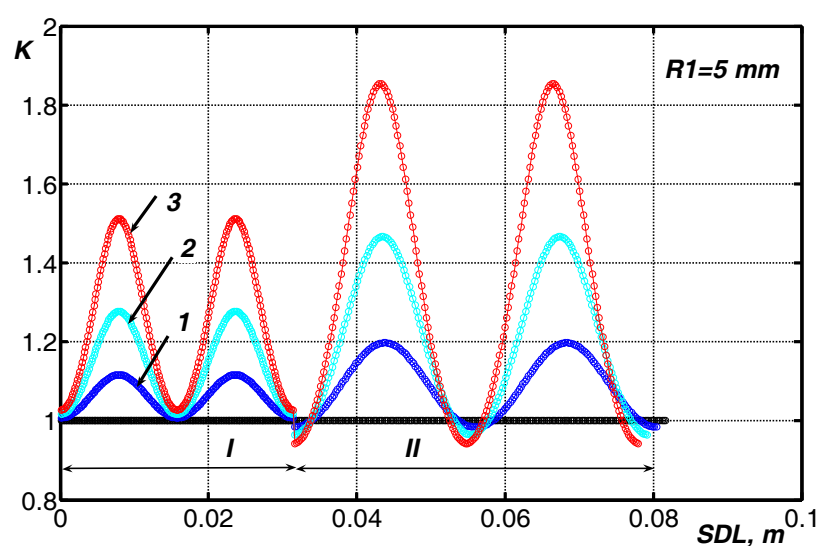

Fig. 7. Coefficient of uneven distribution of the electric field strength on the surface of the conductive wire $(I)$ and insulation (II) in the presence of insulation ellipticity

where $R$ is the total active resistance of the conductive wire and metal screen, $\Omega / \mathrm{m} ; L$ is the total inductance as a sum of internal inductance of the conductive wire and screen and mutual inductance (external), H/m; $G$ is the active conductance of insulation, $\mathrm{S} / \mathrm{m} ; C$ is the cable capacitance, $\mathrm{F} / \mathrm{m} ; \omega=2 \pi f$ is the angular frequency, $\mathrm{rad} / \mathrm{s}$.

In the high frequency range for single-core power cables coaxial structure can assume that $R \leq \omega L$ and $G \leq$ $\omega C$. Then the wave resistance is active and is determined by the simplified formula

$$
Z_{w}=\sqrt{L / C} .
$$

Cable inductance in this range is determined by external inductance only [1]

$$
L \cong L_{\text {out }}=\frac{\mu_{0} \mu}{\pi} \ln \frac{R_{2}}{R_{1}}, \quad C=2 \pi \varepsilon_{0} \varepsilon / \ln \frac{R_{2}}{R_{1}},
$$

where $\mu_{0}=4 \pi \cdot 10^{-7} \mathrm{H} / \mathrm{m}$ is the magnetic constant, $\varepsilon_{0}=8.85 \cdot 10^{-12} \mathrm{~F} / \mathrm{m}$ is the electric constant, $\varepsilon$ is the relative dielectric permittivity of the insulation material, $\mu$ is the magnetic permeability of the conductive materials (for diamagnetics -copper and paramagnetics aluminum $\mu \approx 1$ ).

Fig. 8 shows the change in inductance, capacitance and wave resistance of the coaxial cable design with increasing eccentricity between conductive wire and insulation.

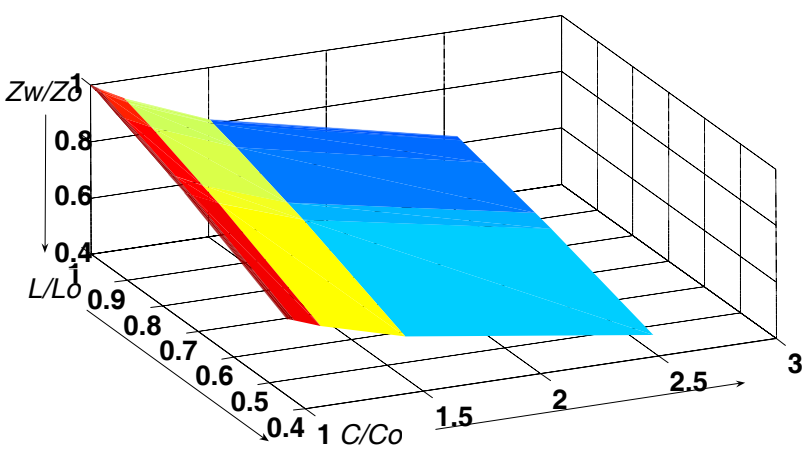

Fig. 8. Effect of eccentricity on the inductance, capacitance and wave resistance of the power cable of coaxial design (indexes «o» show parameters without eccentricity) 
Having a thicker crosslinked polyethylene power cable insulation MV two water treeing spherical shape filled completely (Fig. 9, curve 1, $\varepsilon_{2}=\varepsilon_{3}=80$ ), [6], or partially (Fig. 9, curve 2, $\varepsilon_{2}=\varepsilon_{3}=6.9$ ) with water, leads to an increase in strength is $5-10$ times or more. The basis of the numerical method of calculation of the field strength is Fredholm integral equations of the first and second kind (method of secondary sources) for an axisymmetric field [6].

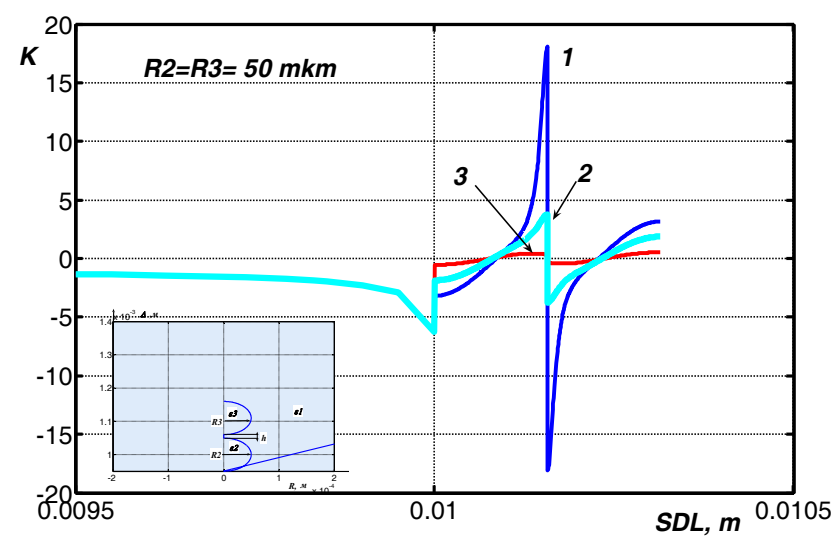

Fig. 9. The influence of the relative permittivity of two spherical inclusions of $100 \mu \mathrm{m}$ in diameter, spaced $2.5 \mu \mathrm{m}$ apart, by a factor of electric field inhomogeneity.

The dielectric constant of polyethylene $\varepsilon_{1}=2.3$

At presence a thicker cross-linked polyethylene insulation of two spherical inclusions, filled with air (Fig. 9, curve $3, \varepsilon_{2}=\varepsilon_{3}=1$ ), the electric field strength on the surface of the inclusions is less than the average value ( $2 \mathrm{kV} / \mathrm{mm}$ for medium voltage power cables).

Influence of the electrical characteristics of the water treeings on the form of probe signals. Degradation of high-power cables with cross-linked polyethylene insulation, laid in the ground, due to the formation of water treeing is a growing problem. Such tree structures clusters [7-9] representing the number of water-filled microcavities with connecting channels, reduce the electric strength of the polymer insulation.

Water treeings (WT) lead to local concentration of electric field in the insulation of crosslinked polyethylene (see Fig. 9), the capacity increase, reduction of insulation resistance, increase of dielectric loss tangent. Thus, the numerical simulation of WT growth in power cables show [10] that the increase in capacity does not exceed $1.5 \%$ in the case of a single elliptical water treeing in full (100\%) germination through the thickness of the insulation (from the metal screen to the conductor) regardless of the design screen performance. Insulation resistance at the same time significant changes: more than an order of magnitude. The result of this change in the insulation resistance is to increase the dissipation factor, conductance and insulation, eventually, decrease in cable impedance. Water treeing are local discontinuities in the structure of polyethylene insulation with wave resistance different from the wave resistance of the main part of the cable. At the distributing by cable high-frequency electromagnetic waves (probe signal - voltage certain of form and frequency) will be observed from the reflection part inhomogeneities that lead to distortion of the (reflectometry in time-domain). To analyze the effect of water treeing in the form of concentrated defect with relevant electrophysical characteristics of the shape of the probe pulse the power cable represented in the form of T-shaped equivalent circuit (Fig. 10) [4]: $R, L$ - resistance and inductance of the cable wires; $C_{0}, R_{0}$ - geometrical capacity (capacity due to rapid polarization modes), and insulation resistance of the leak; $R_{1}, C_{1}$ - parameters due to polarization processes in isolation. The number of units of the equivalent circuit to 1 meter for a correct representation of the cable must be large enough, depending on the operating frequency [4]. Thus, at $1 \mathrm{MHz}$ - not less than 10 . The cable is connected to a source of pulsed EMF $E(t)$ with an internal resistance Re. Resistances $R_{s}$ and $R_{n}$ - resistances of a source and the load respectively.

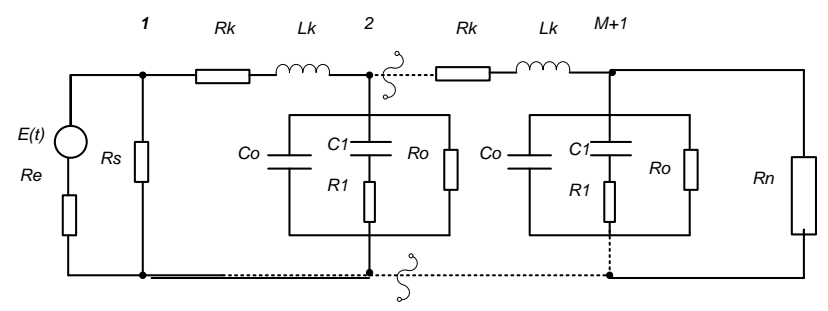

Fig. 10. T-shaped equivalent circuit of the power high-voltage cable of coaxial design [4]

To ensure a consistent mode of operation, excluding the appearance of additional reflected waves influencing the shape of the probe pulse, it is necessary that the equality of load impedances, source and cable impedance. For this purpose, at a frequency of $1 \mathrm{MHz}$, the measurements of the parameters of the sample single-core power cable length $25 \mathrm{~cm}$ АПвГ-1×95/16 for $35 \mathrm{kV}$ with aluminum conductor section $95 \mathrm{~mm}^{2}$ and copper screen section 16 $\mathrm{mm}^{2}: R=0.3262 \Omega ; L=112 \mathrm{nH} ; C=36.3 \mathrm{pF} / \mathrm{m} ; G=0.7 \mu \mathrm{S}$; $\operatorname{tg} \delta=2 \cdot 10^{-3} ; R_{\text {ins }}=10^{12} \Omega \cdot \mathrm{m}$.

Complex wave resistance determined by (1) is practically active: $7.1906 \mathrm{e}+002-5.7684 \mathrm{e}+000 \mathrm{j}$. The real part of 125 times the imaginary component. Wave impedance is $719 \Omega$ module that significantly exceeds the typical values for coaxial cables construction: $93 \Omega, 75 \Omega$ and $50 \Omega$. Complex longitudinal resistance per unit length is $(1.4480+0.0001 \mathrm{j}), \Omega / \mathrm{m}$ : determining a real component due to the resistance contribution of the metallic screen (more than 10,000 times greater than the inductance component). Integrated transverse conductivity per unit length is equal to $(2.8000 \mathrm{e}-006+$ $+4.5216 \mathrm{e}-008 \mathrm{j}) \mathrm{S} / \mathrm{m}$ : the real part is more than 60 times the imaginary (capacitive) component. High values of conductance display screen processes semiconductive insulation and water-swellable tape, and not in the cross-linked polyethylene insulation. The value of the wave resistance, determined according to the simplified formula (2) based on the inductance and capacitance of the cable is equal to $57.5 \Omega$ (close to the value of $50 \Omega)$ ! For a correct simulation of the probing signal 
propagation in the insulation of the power cable characteristic impedance is accepted equal to $57.5 \Omega$.

Measurement data cable parameters are used to determine the parameters of the T-link for a given number $M$ and length $l$ of the cable. The next step is to compile the equivalent circuit cable line method of discrete resistive circuit inductance and capacitance of substitution, taking into account the initial conditions. The next step is made a system of linear algebraic equations (SLAE) of nodal potential method [4]

$$
\bar{G} \cdot \bar{\varphi}=\bar{J}
$$

where $\bar{G}$ is the tree-diagonal matrix of coefficients - own $\left(G_{11}, G_{22}, \ldots, G_{M+1, M+1}\right)$ and mutual $\left(G_{12}, G_{21}, \ldots, G_{M, M+1}\right)$ conductivities of branches

$$
\left(\begin{array}{lllll}
G_{11} & G_{12} & 0 & 0 & \cdots 0 \\
G_{21} & G_{22} & 0 & 0 & \cdots 0 \\
0 & 0 & G_{32} & G_{33} & \cdots 0 \\
\cdots & & & \cdots 0 \\
0 & 0 & 0 & 0 & G_{M+1, M+1}
\end{array}\right),
$$

where $\bar{\varphi}$ is the desired column matrix of nodal potentials, $\bar{J}$ the column matrix of nodal currents.

SLAE is solved by the sweep method. currents are determined at each sampling step, flowing through the inductor and the voltage drop across the containers.

Numerical calculations are performed when connected to a pulsed source of EMF $(E=100 \mathrm{~V})$ power cable line length of $1 \mathrm{~m}$ at a frequency of $1 \mathrm{MHz}$. The duration of the sounding of the rectangular pulse is 4.0 ns. Resistances of the source and load are assumed equal to $57.5 \Omega$.

Fig. 11 shows the behavior of the shape and duration of the probing signal traveling along the cable line: curve 1 - cable with characteristic impedance of $57.5 \Omega$ (measured parameters); curve 2 - cable with wave resistance 48 $\Omega$ (eccentricity between the conductor and insulation); curve 3 - cable with wave resistance of $60 \Omega$ and the isolation parameters: $R_{i n s}=10^{11} \Omega \cdot \mathrm{M}, \operatorname{tg} \delta=2 \cdot 10^{-2}$ (water treeings). Area $I$ is the beginning of the line, area $I I$ is the middle of the line. Influence of dielectric losses (imitation WT) on the shape of the probe pulse is shown in Fig. 12: curve 1 corresponds to $\operatorname{tg} \delta=2 \cdot 10^{-4}$; curve $2-\operatorname{tg} \delta=2 \cdot 10^{-3}$; curve $3-\operatorname{tg} \delta=2 \cdot 10^{-1}$.

\section{Conclusions.}

The presence of the eccentricity and ellipticity in the construction of cable has different effects on the distribution of the electric field strength at the conductor and the insulation. When eccentricity between the wire and the insulation is $10 \%$ of the radius of the core the field strength increases by 1.5 times in the wire and 1.17 times - on the surface of the insulation. The electric field strength on the surface of the insulation is doubled with respect to the strength on the tendon when roundness insulation.

The presence in the thicker crosslinked polyethylene insulation aqueous inclusions spherical shape leads to an increase in tension of 5-10 times the average value of
$2 \mathrm{kV} / \mathrm{mm}$ in the high-voltage power cables. At such electric fields in the cross-linked polyethylene insulation threshold effects occur, in particular, the nonlinear dependence of the density of the current field, the dependence of the dielectric constant of the applied high voltage.

Simulation results show that the presence of water treeings as concentrated with individual heterogeneity characteristic impedance causes a change in shape and duration of the probe signal rectangular.

Time domain reflectometry can be considered as one of the promising methods for diagnosing operational irregularities (ellipticity, eccentricity, water treeing) in high-voltage power cables.

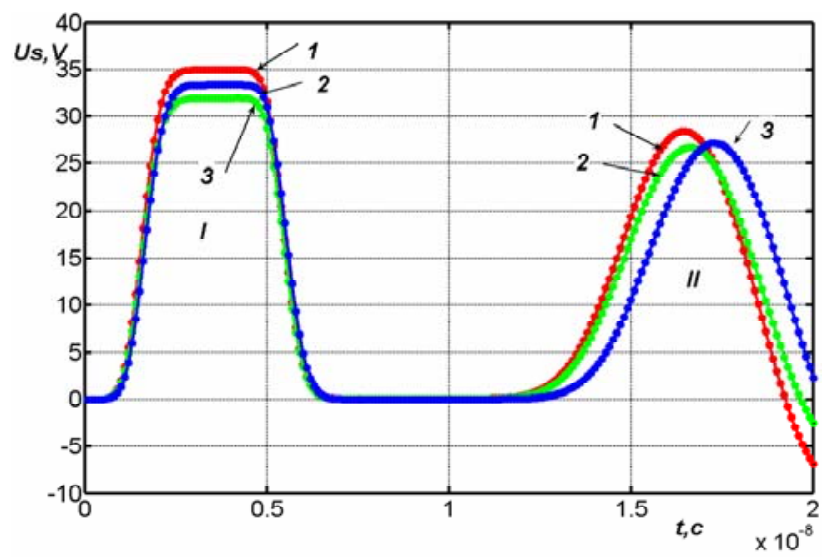

Fig. 11. Character of change of shape and duration probing signal traveling along the cable line in the presence of defects located at a distance $1 / 2$ from the start line

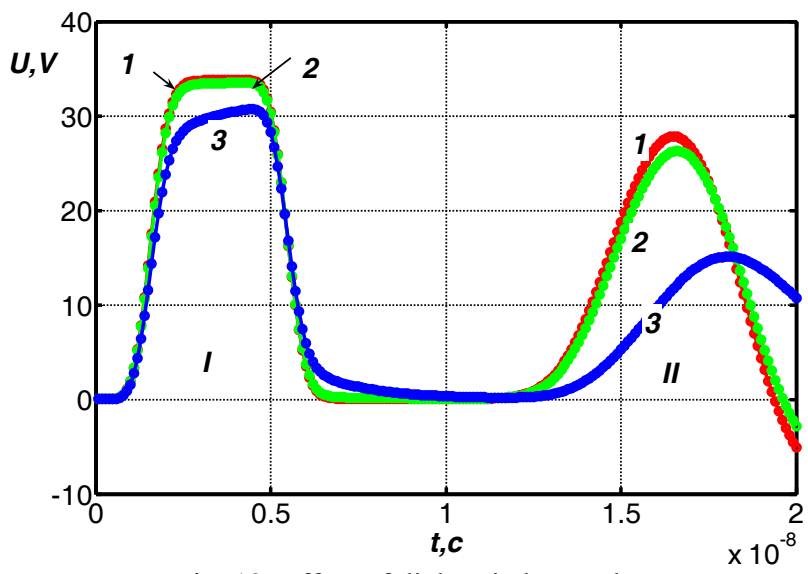

Fig. 12. Effect of dielectric losses due the presence of water treeings on the shape of the probe signal

\section{REFERENCES}

1. Bezprozvannych G.V., Boyko A.N., Kyessayev A.G. Influence of constructive and technological defects on coaxial radiofrequency cable impedance. Electrical engineering \& electromechanics, 2013, no.2, pp. 57-61. (Ukr). doi: 10.20998/2074272X.2013.2.11.

2. Kyessayev A.G. Impact on the transmission parameters eccentricity and ellipticity RF coaxial cables. Bulletin of NTU «KhPI», 2013, no.59, pp. 62-69. (Ukr).

3. Shcherba A.A., Shcherba M.A. Modeling and analysis of the electric field in a dielectric medium, perturbed conductive microscopic inclusions of various sizes and configurations. Tekhnichna Elektrodynamika, 2010, no.6, pp. 3-9. (Rus). 
4. Bezprozvannych A.V, Naboka B.G. Matematicheskie modeli i metody rascheta elektroizoljacionnyh konstrukcij [Mathematical models and methods of calculation electrical insulation constructions]. Kharkov, NTU «KhPI» Publ., 2011. 92 p. (Rus). 5. Bezprozvannych G.V., Naboka B.G., Moskvitin E.S. Substantiation of electrophysical characteristics of high-voltage power cable semiconducting screens with stitched insulation. Electrical engineering \& electromechanics, 2010, no.3, pp. 4447. (Rus). doi: 10.20998/2074-272X.2010.3.10.

6. Bezprozvannych A.V., Kyessayev A.G. Computing experiments for calculation of electrostatic axisymmetric field in piecewise-homogeneous insulation with spherical inclusions. Electrical engineering \& electromechanics, 2014, no.5, pp. 6772. (Rus). doi: 10.20998/2074-272X.2014.5.13.

7. Dissado L.A., Hill, R.M. The fractal nature of the cluster model dielectric response functions. Journal of Applied Physics, 1989, vol.66, no.6, pp. 2511-2524. doi: 10.1063/1.344264.

8. Chen Q., Burkes K., Makram E., Hadidi R., Xu X. Capacitance of Water Tree Modeling in Underground Cables. Journal of Power and Energy Engineering, 2014, vol.02, no.11, pp. 918. doi:10.4236/jpee.2014.211002
9. Bezprozvannych A.V., Kessaev A.G., Shcherba M.A. Frequency Dependence of Dielectric Loss Tangent on the Degree of Humidification of Polyethylene Cable Insulation Tekhnichna Elektrodynamika, 2016, no.3, pp. 18-24. (Rus).

10. Burkes K., Makram E., Hadidi R. Modeling the effect of a water tree inside tape shield and concentric neutral cables. COMSOL Conference, Boston, September 25, 2014. 8 p.

Received 19.09.2016

G.V. Bezprozvannych ${ }^{1}$, Doctor of Technical Science, Professor, A.G. Kyessayev ${ }^{1}$, Postgraduate Student,

${ }^{1}$ National Technical University «Kharkiv Polytechnic Institute», 21, Kyrpychova Str., Kharkiv, 61002, Ukraine, phone +38 0577076010 , e-mail: bezprozvannych@kpi.kharkov.ua

How to cite this article:

Bezprozvannych G.V., Kyessayev A.G. The technological and exploitative factors of local increase of electric field strength in the power cable of coaxial design. Electrical engineering \& electromechanics, 2016, no.6, pp. 54-59. doi: 10.20998/2074-272X.2016.6.09. 